THE INDUSTRIAL INSTITUTE FOR ECONOMIC AND SOCIAL RESEARCH

WORKING PAPER No. 471, 1996

\title{
A SCHUMPETERIAN MODEL OF PROTECTION AND RELATIVE WAGES
}

By Elias Dinopoulos and PaUl SEgerstrom 


\title{
A SCHUMPETERIAN MODEL OF PROTECTION AND RELATIVE WAGES
}

by

Elias Dinopoulos

(University of Florida) and

Paul Segerstrom

(Michigan State University)

October 1996

\begin{abstract}
This paper presents a dynamic general equilibrium model of trade between two advanced countries in which both innovation and skilled acquisition rates are endogenously determined. The model offers a North-North (as opposed to a North-South) trade explanation for increasing relative wage inequality. A global reduction in trade barriers increases R\&D investment and accelerates the pace of technological progress. It also reduces the relative wage of unskilled workers and results in skill upgrading, if and only if $R \& D$ is the skill-intensive activity relative to manufacturing of final products. Trade liberalization does not affect domestic relative prices in either of the two countries.
\end{abstract}

IEL classification: F10, F12, F13, D32, D41

Key words: Economic growth, R\&D, protection, relative wages

Correspondence: Elias Dinopoulos, Department of Economics, University of Florida. Gainesville, FL 32611. Phone: (352)392-8150; Fax: (352)392-7860; E-mail: dinopoe@dale.cba.ufl.edu 

"The sources of U.S. difficulties are overwhelmingly domestic, and the nation's plight would be much the same even if world markets had not become more integrated ... less skilled workers in particular are suffering because a high-technology economy has less and less demand for their services. Our trade with the rest of the world plays at best a small role." Krugman and Lawrence (1994).

\section{Introduction}

Recent developments in global labor markets have captured the interest of many labor and international economists. ${ }^{\prime}$ Many empirical studies have documented the following changes that occurred during the 1980 s and that will be referred to as stylized facts (SF) in the present paper. SF(1): The wage of unskilled workers has declined relative to the wage of skilled workers. $^{2}$ SF(2): The employment of skilled workers as a fraction of total employment has increased across all manufacturing industries. ${ }^{3} \mathrm{SF}(3)$ : The shift in employment from unskilled to skilled workers has occurred mostly within (as opposed to between) four-digit manufacturing industries. ${ }^{4} \mathrm{SF}(4)$ : There has been an acceleration of technological change and an increase in R\&D expenditures. ${ }^{5} \mathrm{SF}(5):$ The global economy has experienced a dramatic increase in openness measured by trade shares. ${ }^{6} \mathrm{SF}(6)$ : Domestic prices have remained roughly constant despite the increase in trade volume. ${ }^{7} \mathrm{SF}(7)$ : The above mentioned changes have been global in character rather than strictly U.S. based developments. ${ }^{8}$

The search for principal causes of the above-mentioned stylized facts has generated an important debate among economists. Given SF(5), economists initially focused on the role that global integration could have played in explaining SF(1). Early empirical studies established a negative correlation between the volume of imports and the relative demand for unskilled workers. ${ }^{9}$ This finding was interpreted as a manifestation of the Stolper-Samuelson (1941) theorem which states that a decline in the relative price of the importable good must reduce the 
return to the factor of production that is used intensively in its production. The StolperSamuelson theorem implies that increased trade between a developed (skilled labor abundant) country and a developing (unskilled labor abundant) country puts downward pressure on the relative wage of unskilled workers in the developed country. This North-South trade explanation, however, was successfully challenged by several international economists who pointed out that the Stolper-Samuelson mechanism operates through changes in domestic prices and $\mathrm{SF}(6)$ was a sufficient condition to rule out this particular explanation for the rise in wage inequality. ${ }^{10}$

These economists also noted that significant intersectoral shifts in employment did not occur [SF(2) and SF(3)], and therefore trade liberalization could not be held accountable for changes in the wage structure. By default, unskilled-labor saving technological change became the dominant explanation for the global decline in the relative demand and the wage of unskilled workers."

While it is not our purpose to dismiss the role of computers (and information technology more generally) as a contributing factor in reducing the demand for low-skilled workers, we will argue that the role of trade liberalization has been underestimated. Instead of using the traditional Heckscher-Ohlin-Samuelson model with perfectly competitive markets and intersectoral trade based on differences in factor abundance, we develop a Schumpeterian model of North-North trade between structurally similar developed countries. We find that trade liberalization, by itself, can account not only for the observed increase in relative wage inequality SF(1), but also for all six of the-other previously-mentioned stylized facts.

The Schumpeterian model of the paper consists of two countries. Individuals differ in their abilities within each country. An individual can work as an unskilled worker from the time she is born and receive the unskilled wage independently of her ability for the duration of her 
life. Alternatively, she can undergo "training," for an exogenous period of time without earning any income, and become a skilled worker receiving a wage proportional to her ability. The decision to become a skilled worker is endogenous and depends on the relative wage of skilled workers. Individuals with high levels of ability become skilled and constitute the supply of skilled labor.

There is a continuum of industries where firms produce final consumption goods using both unskilled and skilled labor. In each industry, firms can upgrade the quality of their products by investing in R\&D. The arrival of innovations, that are associated with higher quality products, is governed by a Poisson process whose intensity is proportional to R\&D investment. ${ }^{12}$ Free entry into each $R \& D$ race results in zero expected discounted profits. A firm that wins an $R \& D$ race is awarded a patent that enables the innovative firm to earn temporary monopoly profits from selling exclusively its state-of-the-art quality product in both countries. This patent expires when further innovation occurs in the same industry. Thereafter, the previously patented product is competitively produced by firms in both countries.

We assume that both countries (Home and Foreign) are structurally identical and impose the same ad valorem tariff on all imported goods. Even though both countries are structurally identical, state-of-the-art quality products are traded in equilibrium. Half of the world industries have Home quality leaders and half have Foreign quality leaders at each instant in time. These products are exported and compete against lower quality domestically produced goods. ${ }^{13}$

Global trade liberalization (caused by a reduction in the common tariff) increases the volume and the value of imports (and exports) as a percentage of each industry's shipments. However, trade liberalization does not affect domestic or foreign consumer prices (Proposition 1). Relative product prices remain unchanged because the demand in each industry is unitary elastic by assumption, and products within each industry are perfect substitutes. These are 
standard features in growth models based on quality improvements. Each quality leader can charge a price that is proportional to her unit cost (the price of followers) with the factor of proportionality equal to a parameter capturing the size of each innovation (the quality increment). A reduction in tariffs increases the profit margin of each state-of-the-art quality product, but does not affect the price charged expressed in units of domestically produced goods.

Another result of the paper reveals a Schumpeterian version of the Stolper-Samuelson (1941) mechanism which relates changes in the reward (the "price") of an innovation to changes in the relative wage of unskilled and skilled workers. An increase in the expected discounted profits of an innovation increases permanently the wage of skilled workers and reduces the wage of unskilled workers if and only if $R \& D$ is the skill intensive activity relative to manufacturing (Lemma 1). The Schumpeterian component of this mechanism refers to the "price" of an innovation which is proportional to the flow of temporary monopoly profits. The StolperSamuelson component refers to the intensity ranking between the two activities that determines which of the two factors of production is hurt if the relative "price" of innovation increases.

Proposition 1 and Lemma 1 imply that trade liberalization can increase the profitability of innovations and the trade volume and hurt unskilled workers if R\&D is the skilled intensive activity. Relative good prices remain unaffected in this process. A decline in the relative wage of unskilled workers reduces the fraction of workers who choose to remain unskilled and increases the fraction of population that becomes skilled workers. The assumptions of full employment, structurally identical industries and countries imply that these changes in employment occur strictly within each industry and not across industries. Therefore, trade liberalization increases the skill abundance in both countries and generates across-the-board skill upgrading as a result of a decline in the wage of unskilled workers. Finally, an increase in R\&D profitability caused by trade liberalization shifts resources from manufacturing to R\&D and 
accelerates the pace technology progresses. Theorem 1 states these results formally.

Although trade liberalization is consistent with all seven stylistic facts, we briefly examine other causes that could increase the "profitability" of innovation. For example, expected discounted profits could increase as a result of exogenous technical change in the provision of $R \& D$ services, or, due to an increase in the size of innovations (loosely related to an exogenous boost of technological change). As it turns out, the value of imports (exports) as a share of consumption expenditure depends only on protection and the size of innovations. An increase in the size of innovations reduces the share of imports and increases the relative price of the state-of-the-art products (e.g. the domestic price of imports). Exogenous technical change in R\&D services leaves the share of imports unaffected. Thus, these alternative causes fail to pass $\mathrm{SF}(5)$, leaving the North-North trade liberalization as the most likely single explanation that is consistent with all seven stylized facts.

Section 2 develops the model and states Proposition 1 and Lemma 1. Section 3 analyzes the effects of global trade liberalization. The conclusions of the paper are stated in section 4 and many algebraic details are relegated to Appendix A.

\section{The Model}

This section develops a two-country dynamic general equilibrium model with the following features. The innovation process, taste structure, and the removal of growth scale effects (to be explained below) are borrowed from Dinopoulos and Segerstrom (1996). In addition, building on earlier work on human capital acquisition by Findlay and Kierzkowski (1983) and Borsook (1987), we explicitly model and endogeneize the skill acquisition process. We also allow both factors of production (unskilled and skilled labor) to be employed in both activities (R\&D investment and manufacturing of final products). Moreover, we assume Coumot competition in quantities in final good markets unlike all previous quality ladder growth models 
that assume Bertrand competition in prices instead. Finally, we assume that only state-of-the-art quality products are protected by patents, instead of examining the case of infinite patent protection.

\subsection{Household Behavior and Skill Acquisition}

There is a continuum of households in each country indexed by ability $\theta \in[0,1]$. All members of household $\theta$ have the same ability level equal to $\theta$, and all households have the same number of members at each point in time. Each household is modelled as a dynastic family whose size grows over time at an exogenously given rate $n=\beta-\delta>0$, where $\beta$ is the birth rate and $\delta$ is the death rate. Each individual lives for an exogenously given period of time $D>0$.

Letting $\mathrm{N}_{0}$ denote the number of members of each household at time $t=0$, the population size in each country at time $t$ is $N(t)=N_{0} e^{n t}$. Because the number of births at time $t$ equals the number of deaths at time $t+D$ [i.e. $\delta N(t+D)=\beta N(t)$ for all $t$, it follows that $\delta=n /\left(e^{n D}-1\right)$ and $\beta=$ $n e^{n D /\left(e^{n D}-1\right)}$.

Family optimization considerations determine the allocation of income across final goods, the evolution of consumption expenditure over time, and the decision whether to become skilled or enter the labor force as unskilled workers. In making these decisions, each family takes prices of final products, wages, and the interest rate as given.

The abiiity level $\theta$ is known to both firms that hire workers and to each worker herself. A worker can enter the labor force as unskilled and earn the wage $w_{L}$ independently of her ability for the duration of her life D. Alternatively, a worker with ability $\theta$ can enter the labor force after spending an exogenously given period of time T < D in "training" to become skilled. A skilled worker with ability $\theta$ earns a wage $w_{H} \theta$ for a period $D-T>0$, and does not earn any income during her training or apprenticeship. The marginal return per unit of skill $w_{H}$ is independent of the level of ability $\theta$. We assume, for simplicity, that the training process does 
not require any real resources, and therefore the opportunity cost of becoming a skilled worker equals the discounted value of foregone unskilled wage income. We also assume that income is evenly shared within each family (between employed and trainees) so that, at each point in time, consumption expenditure is the same for each living member of a family..$^{14}$

The optimization problem of a family with ability $\theta$ is:

$$
\max _{q_{\theta}} U_{\theta} \equiv \int_{t}^{\infty} N_{0} e^{-(\rho-n) s} \log u_{\theta}(s) d s,
$$

subject to the following constraints

$$
\begin{gathered}
\log u_{\theta}(s) \equiv \int_{0}^{1} \log \left[\sum_{j} \lambda^{j} q_{\theta}(j, \omega, s)\right] d \omega \\
c_{\theta}(s) \equiv \int_{0}^{1}\left[\sum_{j} p(j, \omega, s) q_{\theta}(j, \omega, s)\right] d \omega \\
W_{\theta}(t)+z_{\theta}(t) \equiv \int_{t}^{\infty} N_{0} c_{\theta}(s) e^{n s} e^{-[R(s)-R(t)]} d s
\end{gathered}
$$

Equation (1) is the discounted utility of a household with ability $\theta$, where $\rho>0$ is the constant subjective discount rate, $n>0$ is the exogenous rate of population growth, and $\rho-n>$ 0 is required for the integral in (1) to be well defined. Equation (2) defines the instantaneous utility function of each household member, where $q_{\theta}(j, \omega, s)$ denotes the quantity consumed by an individual with ability $\theta$ of a good with $\mathrm{j}$ improvements (innovations) in its quality in industry $\omega$. $\epsilon[0,1]$ at time s. The parameter $\lambda>1$ captures the size of each quality improvement and $\lambda^{j}$ denotes the total quality of a good after $\mathrm{j}$ innovations. Equation (2) is standard in quality-ladder growth models with a continuum of industries.

Equation (3) states that per capita consumption expenditure $c_{\theta}(s)$ at time $s$ must equal the value of all final goods consumed, where $p(j, \omega, s)$ and $q_{\theta}(j, \omega, s)$ denote the price and quantity of a final product with $\mathrm{j}$ improvements in its quality in industry $\omega$ at time s. Finally, equation (4) states the standard intertemporal budget constraint. $W_{\theta}(t)$ is the family's discounted wage 
income from time $t$ on, and $Z_{\theta}(t)$ is the value of the family's financial assets at time $t$. (In this model, some firms earn positive profits which are paid to the families that own these firms.) The right-hand-side (RHS) of (4) equals the discounted value of family's consumption from time $t$ to infinity, and $R(t) \equiv \int_{0}^{t} r(s) d s$ is the market discount factor with $\dot{R}(t)=r(t)$ denoting the instantaneous interest rate at time $t^{15}$

Appendix B, which is available upon request, derives formally the solution to the family's dynamic optimization problem. This problem can be solved in three steps. First, maximizing subutility (2) subject to the expenditure constraint (3) yields unit elastic demand for those products in each industry with the lowest quality adjusted prices. Because all products within an industry are perfect substitutes by assumption, only products with the lowest quality adjusted prices are purchased by consumers. Second, maximizing discounted utility (1) subject to the intertemporal budget constraint (4), taking the discounted wage income of the family $W_{\theta}(t)$ as given, we obtain the usual condition

$$
\frac{\dot{c}_{\theta}(t)}{c_{\theta}(t)}=r(t)-\rho .
$$

The differential equation (5) states that per capita consumption expenditure grows over time if and only if the market interest rate exceeds the subjective discount rate.

Third. training/employment decisions are made to maximize each family's discounted wage income. The complexity of the model renders the analysis of transitional dynamics intractable, and therefore we will focus on the balanced growth equilibrium for the most part of the paper. At the steady-state equilibrium, a family member with ability $\theta$ born at time $t$ undergoes training and becomes a skilled worker if and only if

$$
\int_{t}^{t+D_{e}-\rho(s-t)} w_{L} d s<\int_{t+T}^{t+D_{e}-\rho(s-t)} \theta w_{K} d s .
$$

The LHS of inequality (6) equals the discounted wage income of an individual from working as an unskilled worker from time $t$ until her death at time $t+D$, where $r(t)=\rho$ and $w_{L}, w_{H}$ remain 
constant over time. The RHS of (6) is the lifetime income of a skilled worker, who earns zero income during her training period and $\theta w_{H}$ from time $t+T$ until time $t+D$, discounted to time $t$.

Condition (6) can be used to determine endogenously the division of population among skilled and unskilled workers. Because the RHS of (6) increases in $\theta$, whereas the LHS is independent of $\theta$, there exists a level of ability denoted by $\theta_{0}$ such that (6) holds as an equality. All families (and individuals) with ability lower than $\theta_{0}$ choose to remain unskilled, and all families with ability greater than $\theta_{0}$ undergo training and enter the labor force as skilled workers. Setting (6) to hold as an equality and solving for the long-run value of $\theta_{0}$, we obtain

$$
\theta_{0}=\left[\frac{1-e^{-\rho D}}{e^{-\rho T}-e^{\rho D}}\right] \frac{w_{L}}{w_{H}}=\sigma \frac{w_{L}}{w_{H}}
$$

where $\sigma$ is the expression in square brackets in (7). Because $\sigma>1$ and $0<\theta_{0}<1$ always holds in equilibrium (as we will later establish), equation (7) implies that $w_{H} \theta_{0}>w_{L}$ and that $w_{H} / w_{L}>1$. The wage of a skilled worker must always be higher than the wage of any unskilled worker. An increase in the duration of training $T$ or in the relative wage of unskilled workers $w_{L} / w_{H}$ raises the fraction of population that chooses to remain unskilled $\theta_{0}$. The supply of unskilled labor in each country at time tequals the members of population that choose to remain unskilled

$$
L(t)=\theta_{0} N(t)
$$

The labor endowment of skilled workers at each instant in time $H(t)$ is derived as follows: A fraction $\left(1-\theta_{0}\right)$ of each country's population train and become skilled workers, and therefore $\left(1-\theta_{0}\right) N(t)$ individuals either work as skilled workers or are training to become skilled workers in each country at time t. In this subpopulation, the skilled workers are the older individuals. namely, those individuals that were borm between $t-D$ and $t-T$ :

$$
\int_{t-D}^{t-T} \beta\left(1-\theta_{0}\right) N(s) d s=\left(1-\theta_{0}\right) \phi N(t),
$$

where $\phi=\left[\mathrm{e}^{\mathrm{n}(\mathrm{D}-\pi)}-1\right] /\left[\mathrm{e}^{\mathrm{nD}}-1\right]<1$. The average skill level of workers that have finished 
training equals $\left(1+\theta_{0}\right) / 2$, and therefore the supply of skilled labor, measured in efficiency units, at time $t$ is given by

$$
H(t)=\frac{\left(1+\theta_{0}\right)}{2}\left(1-\theta_{0}\right) \phi N(t)=\frac{\left(1-\theta_{0}^{2}\right)}{2} \phi N(t)
$$

where $\phi<1$ depends only on the parameters of the model. ${ }^{16}$

It is obvious from equations (7), (8) and (9) that a decline in the relative wage of unskilled workers decreases $\theta_{0}$ and $L(t)$ and increases $H(t)$ resulting in a rise of skilled labor abundance $H(t) / L(t)$ in each country. This is a standard result in models with variable factor endowments (e.g. Findlay and Kierzkowski (1983) and Borsook (1987)). In the long-run, each economy's factor endowments grow at the same rate as the global population because $\theta_{0}$ is constant over time:

$$
\dot{H}(t) / H(t)=\dot{L}(t) / L(t)=\dot{N}(t) / N(t)=n .
$$

\subsection{Product Markets and Trade}

There is a continuum of industries in each country indexed by $\omega \in[0,1]$. Manufacturing of final products uses unskilled and skilled labor (measured in efficiency units) according to a constant returns to scale technology described by the following cost function:

$$
F_{Q}=A\left(w_{L}, w_{H}\right) Q,
$$

where $A\left(w_{L}, w_{H}\right)$ is the unit cost function and $Q$ is the total output produced. $A\left(w_{L}, w_{H}\right)$ is an increasing and concave function with $A_{L}=\partial A / \partial w_{L}$ and $A_{H}=\partial A / \partial w_{H}$ denoting the unskilled and skilled labor requirement per unit of output respectively. We assume that $(10)$ is identical across industries and across different quality levels, and we will use the marginal (and average) costs of manufacturing as the numeraire in the model:

$$
A\left(w_{L}, w_{H}\right)=1
$$

We will refer to firms producing the state-of-the-art quality product in an industry as quality leaders, as opposed to quality followers that know how to produce a product of quality 
one step below the highest quality good. When a firm wins an R\&D race and becomes a quality leader, it receives a patent to exclusively produce the new product and sell it to all consumers in the world. This patent expires when further innovation occurs in the industry. All products that are not protected by patents can be produced competitively in both countries. ${ }^{17}$

We assume that both countries impose a common ad-valorem tariff $\tau$ on all imports. This common tariff is the only policy instrument used, and the tariff revenues are distributed to consumers in a lump-sum fashion. Firms take the common tariff as given when maximizing profits. Each quality leader has market power because it holds a patent protecting the state-ofthe-art quality product in each industry. Unlike other models of growth through quality improvements that assume Bertrand price competition, we assume that each quality leader competes with quality followers in a Cournot fashion by setting quantities.

Consider a Home quality leader that engages in Cournot competition with foreign and domestic followers. The analysis of a Foreign quality leader is identical because of structural symmetry between the two countries. Because unit costs of all followers are identical (and equal to unity), any positive tariff imposed by the Foreign government on imports from Home becomes prohibitive for Home followers. Given this market segmentation in inferior quality products, the Home quality leader competes in the Foreign market only with Foreign followers, and in the Home market only with Home followers.

In the Foreign market the Home leader faces an ad valorem tariff $\tau>0$. Denote with $Q_{i}$ the output of the Home leader sold in the foreign market, and let $Q_{f}$ be the output of Foreign followers. We will denote with an asterisk variables and functions in the Foreign country. Because the Home quality leader produces a good $\lambda$ times the quality of the good produced by followers, consumer arbitrage requires that $p_{\ell}(1+\tau)=\lambda p_{f}$ iwhere $p_{\ell}$ is the Home consumer price of the state-of-the-art quality product, $p_{l}(1+\tau)$ is the domestic price of the same 
good in the Foreign country, and $\mathrm{p}_{\mathrm{f}}{ }^{-}=A\left(w_{L}, w_{H}\right)=1$ is the price charged by Foreign followers since free entry prevails in the inferior quality product market. The market demand for a typical product is unitary elastic and therefore

$$
\frac{c^{*}(t) N^{*}(t)}{P_{l}(1+\tau)}=Q_{i}^{*}+Q_{f}^{*} / \lambda
$$

where $c^{*}(t)$ is the economy-wide consumption per capita expenditure in the Foreign country. The RHS of (12) equals total quantity demanded expressed in units of the state-of-the-art quality product (i.e. one unit of $Q_{i}{ }^{*}$ is equivalent to $1 / \lambda$ units of $Q_{f}{ }^{*}$ ).

Assumption (11) implies that the instantaneous profits of a Home leader earned in the Foreign market are:

$$
\pi_{i}^{*}=p_{1} Q_{i}^{*}-Q_{i}^{*}=\frac{c^{*}(t) N^{*}(t) Q_{i}^{*}}{(1+\tau)\left(Q_{i}^{*}+Q_{i}^{*} / \lambda\right)}-Q_{i}^{*}
$$

where (12) has been used to substitute for $p_{\ell}$. Maximizing (13) with respect to $Q_{\ell}$ yields the best reply function of the Home quality leader in implicit form:

$$
\frac{\partial \pi_{i}^{*}}{\partial Q_{i}^{*}}=0: \frac{c^{*}(t) N^{*}(t) Q_{f}^{*}}{(1+\tau) \lambda}=\left(Q_{i}^{*}+Q_{f}^{*} / \lambda\right)^{2}
$$

Because perfect competition prevails among Foreign followers, the zero-profit condition

$$
p_{f}^{*}=1 \text { determines the price of imports in the Foreign market } p_{d}(1+\tau)=\lambda p_{f}=\lambda \text {. }
$$

Therefore, we have

$$
\frac{c^{*}(t) N^{*}(t)}{\lambda}=Q_{i}^{*}+Q_{f}^{*} / \lambda
$$

Solving (14) and (15), we obtain the Cournot equilibrium quantities of imports $Q_{\ell}{ }^{*}$ and domestic production $Q_{\mathrm{f}}$ in the Foreign market:

$$
\begin{gathered}
\dot{Q}_{i}^{*}=\frac{c^{*}(t) N^{*}(t)}{\lambda^{2}}(\lambda-1-\tau) \\
Q_{i}{ }^{*}=\frac{c^{*}(t) N^{*}(t)}{\lambda}(1+\tau)
\end{gathered}
$$

Substituting (16) and (17) into (13) yields an expression for the equilibrium instantaneous profits 
of a Home quality leader from exports

$$
\pi_{i}^{*}=\frac{c^{*}(t) N^{*}(t)(\lambda-1-\tau)^{2}}{(1+\tau) \lambda^{2}}
$$

Because a Home quality leader faces segmented markets, the analysis of Cournot quantity competition in the Home market is identical to the analysis in the Foreign market where $\tau=0$. Therefore, in the domestic market a Home quality leader charges a price equal to $p_{\ell}=\lambda$, Home followers make zero profits and charge $p_{f}=1$, and the quantities produced are given by

$$
\begin{gathered}
Q_{f}=\frac{c(t) N(t)}{\lambda} \\
Q_{l}=\frac{c(t) N(t)(\lambda-1)}{\lambda^{2}} .
\end{gathered}
$$

The maximum instantaneous profits of a Home quality leader at Home are obtained by setting $\tau=0$ in (18)

$$
\pi_{l}=\frac{\mathrm{c}(\mathrm{t}) \mathrm{N}(\mathrm{t})(\lambda-1)^{2}}{\lambda^{2}},
$$

where $c(t)$ and $N(t)$ are consumption expenditure per capita and population in the Home country.

Structural symmetry across the two countries implies that $c(t)=c^{*}(t)$ and $N(t)=N^{*}(t)$. Therefore, each quality leader (Home or Foreign) exports the state-of-the-art quality product and obtains global instantaneous profits

$$
\pi=\pi_{l}^{*}+\pi_{l}=c(t) N(t)\left[\frac{(\lambda-1-\tau)^{2}}{(1+\tau) \lambda^{2}}+\frac{(\lambda-1)^{2}}{\lambda^{2}}\right]
$$

There are several interesting features of the Cournot product market equilibrium. First. only the state-of-the-art quality products are traded. In other words, the quality of imported goods is always higher than the quality of domestically produced goods. The pattern of trade depends on whether a Home or a Foreign firm becomes a quality leader, an event that is purely random because the equilibrium level of $R \& D$ investment is the same in both countries. Bhagwati (1995) has proposed the notion of "Kaleidoscopic" comparative advantage which is similar to the present formulation of R\&D generated trade. Second, all followers charge the 
same price $p_{f}=p_{f}^{*}=1$ which is used as the numeraire, and all quality leaders charge a price equal to $p_{l}=p_{i}^{*}=\lambda$ since they are constrained by domestic production of inferior quality goods that are perfect substitutes. Third, trade liberalization caused by a reduction in $\tau$ does not have any effects on prices (domestic and international), but increases imports (exports) and instantaneous global profits of quality leaders. A reduction in the common tariff reduces the domestic output and manufacturing employment in protected markets. The common tariff becomes prohibitive for $\tau \geq \lambda-1$, and therefore we will assume that $0 \leq \tau \leq \lambda-1$ in subsequent analysis.

The value of imports (exports) as a percentage of consumption expenditure is an appropriate measure of trade liberalization that captures the economy's openness:

$$
\frac{Q_{i} \cdot \lambda}{Q_{i} \lambda+Q_{f}^{*}}=1-\frac{(1-\tau)}{\lambda} .
$$

The following proposition states the conclusions of the above-mentioned remarks:

Proposition 1: Trade liberalization increases the openness of each economy measured by (23), but has no effect on domestic and international prices. An exogenous increase in the size of innovations $\lambda$ decreases the openness of each economy and raises the domestic price of imported goods.

Proposition 1 reveals that trade liberalization can increase the openness of the global economy without affecting relative domestic prices in imperfectly competitive markets with vertical product differentiation. Although it does not affect conventional relative prices, trade liberalization increases the relative "price" of innovation by increasing global instantaneous profits. 


\section{$2.3 \quad R \& D$ Races}

There are sequential and stochastic $R \& D$ races in each industry $\omega \in[0,1]$. These races result in the discovery of higher quality final products. Unskilled and skilled labor are combined through a constant returns to scale production function to generate $R \& D$ services. Workers are perfectly mobile across industries and activities with unskilled workers performing unskilled jobs and with skilled workers performing skilled jobs. All firms participating in a race face the same production function of $R \& D$ services, and there is free entry into each race. R\&D services are not traded between the two countries by assumption.

A firm $i$ which engages in R\&D in industry $\omega$ at time $t$ and discovers the next higher quality product with instantaneous probability $I_{i}(\omega, t) d t$, incurs the $R \& D$ cost flow:

$$
F_{i}=\left[B\left(w_{L}, w_{H}\right) X(\omega, t)\right] I_{i}(\omega, t)
$$

where $B\left(w_{L}, w_{H}\right)$ is a standard unit cost function derived from a constant returns to scale production function, and $X(\omega, t)$ is a function that captures the difficulty of conducting $R \& D$. The term in square brackets equals the unit cost of $R \& D$ services $I_{i}(\omega, t) .^{18}$

We assume that the returns to $R \& D$ investment are independently distributed across firms, across industries and over time. Therefore, the industry-wide instantaneous probability of success in industry $\omega$ at time $t$ is $I(\omega, t) d t=\left[\Sigma_{i}(\omega, t)\right] d t$ in the Home country and $I^{*}(\omega, t) d t=\left[\underset{i}{\left.\Sigma I_{i}{ }^{*}(\omega, t)\right] d t}\right.$ in the foreign country. Thus the arrival of innovations in each industry is governed by a Poisson process whose intensity equals the global amount of R\&D services $\left(I(\omega, t)+I^{*}(\omega, t)\right)$. Higher levels of R\&D investment increase the expected frequency of innovations and result in an acceleration of technological progress.

We assume two alternative specifications of $X(\omega, t)$ in order to remove the intertemporal scale effects of growth and add more empirical relevance to the growth component of the model. In the first specification, $R \& D$ starts being equally difficult in all industries $(X(\omega, t)=1$ for all 
$\omega)$, and the level of R\&D difficulty grows according to

$$
\frac{\dot{X}(\omega, t)}{X(\omega, t)}=\mu\left[I(\omega, t)+I^{*}(\omega, t)\right]
$$

where $\mu>0$ is a constant. This specification of R\&D difficulty captures the notion that ideas that are easier to discover tend to be discovered earlier in time. ${ }^{19}$ We call the resulting model the TEG one because trade liberalization has only "temporary effects on growth."

In the second specification, the difficulty of conducting R\&D is proportional to the size of the global market measured by the number of consumers in both countries

$$
\mathrm{X}(\omega, \mathrm{t})=\mathrm{kN}(\mathrm{t}), \quad(\mathrm{PE} G)
$$

where $k>0$ is a constant. This specification captures the idea that it is more difficult to introduce successfully new products and to replace old ones in a larger market. ${ }^{20}$ We call the resulting model the PEG one because trade liberalization has "permanent effects on growth".

There is a global stock market that channels consumer savings to firms engaged in R\&D. Because there is a continuum of industries with simultaneous $R \& D$ races, consumers can diversify completely the industry-specific risk and receive the instantaneous interest rate $r=\rho$. Each firm engaged in R\&D issues a security that pays the flow of monopoly profits if the firm wins the $R \& D$ race and zero if it does not win the race. Let $v(t)$ denote the expected discounted profits of a successful firm (i.e. quality leader) in industry $\omega$ at time t. Over a time interval dt. the shareholder of a stock issued by a successful $R \& D$ firm receives a dividend $\pi(t) d t$ and the value of the firm appreciates by $d v(t)=\dot{v}(t) d t$. Because each quality leader is targeted by R\&D firms in both countries that try to discover the next higher quality product, this shareholder suffers a loss $v(t)$ if further innovation occurs. This event occurs with instantaneous probability $\left(I(t)+I^{*}(t)\right) d t$. whereas the event of no innovation occurs with probability $I-\left(I(t)+I^{*}(t)\right) d t$. Efficiency in the stock market requires that the expected rate of return of a stock issued by a successful R\&D firm must be equal to the riskless rate of return which is the instantaneous 
interest rate:

$$
\frac{\pi(t) d t}{v(t)}+\frac{\dot{v}(t)}{v(t)}\left[1-\left(I(t)+I^{*}(t)\right) d t\right] d t-\frac{(v(t)-0)}{v(t)}\left[I(t)+I^{*}(t)\right] d t=r d t
$$

Taking limits as $\mathrm{dt}-0$, we obtain

$$
v(t)=\frac{\pi(t)}{r-I(t)+I^{*}(t)-(\dot{v}(t) / v(t))} .
$$

Global instantaneous profits earned by quality leaders are appropriately discounted using the instantaneous market interest rate, the instantaneous probability of being driven out of business by further innovation (the creative-destruction effect), and the growth of expected discounted profits due to economic expansion caused by population growth.

Denote with $v(\omega, t)$ the expected discounted value of monopoly profits (27) in industry $\omega$ at time $t$, and consider firm $i$ located in the Home country and engaged in R\&D. That firm chooses R\&D services $I_{i}$ to maximize expected discounted profits.

$$
v(\omega, t) I_{i}(\omega, t) d t-B\left(w_{L}, w_{H}\right) X(\omega, t) I_{i}(\omega, t) d t
$$

where $v(\omega, t)$ can be thought of as the "price" of an innovation and the second term equals the instantaneous costs of producing $I_{i}(\omega, t) R \& D$ services. Free entry into each $R \& D$ race drives the expected discounted profits down to zero and generates the following R\&D condition:

$$
S(\omega, t)=\frac{v(\omega, t)}{X(\omega, t)}=B\left(w_{L}, w_{H}\right)
$$

Abstracting from $X(\omega, t)$, which serves the purpose of removing the scale effects, expression $S(\omega, t)$ can be thought of as the "relative price" of an innovation because $v(\omega, t)$ is the expected discounted profits of a quality leader. Letter S stands for "Schumpeter-Stolper-Samuelson" and denotes the Schumpeterian version of the Stolper-Samuelson (1941) mechanism which is stated in the following lemma.

Lemma 1: In the absence of factor intensity reversals, an increase in the reward to $R \& D$ 
investment measured in terms of domestically produced goods by quality followers $S(\omega, t)$ :

(i) raises the wage of the factor of production that is used intensively in $R \& D$ investment, and lowers the wage of the factor of production that is used intensively in manufacturing of final goods.

(ii) decreases the fraction of population that chooses to remain unskilled $\theta_{0}$ if and only if $R \& D$ is the skill intensive activity.

Proof: See Appendix A.

Figure 1 illustrates the determination of wages for the case of $R \& D$ investment being the skill intensive activity relative to manufacturing of final products. Concavity of unit cost functions $A\left(w_{L}, w_{H}\right)$ and $B\left(w_{L}, w_{H}\right)$ imply that equations (11) and (28) generate convex and downward-sloping graphs in the $w_{H}, w_{L}$ space for any given value of the innovation price $S$. In the absence of factor intensity reversals, the slope of $B\left(w_{L}, w_{H}\right)=S$ graph is flatter than that of $A\left(w_{L}, w_{H}\right)=1$ reflecting the assumption that $R \& D$ is the skill intensive activity. The unique intersection of the two graphs at point $E_{0}$ determines the equilibrium wages $w_{H}$ and $w_{L}$. Point $E_{1}$ that lies above the 45 degree line is the intersection of $A\left(w_{L}, w_{H}\right)=1$ and line $w_{H}=\sigma w_{L}$. The latter is defined by setting $\theta_{0}=1$ in equation (7) and imposes a lower bound on the relative wage of skilled labor. ${ }^{21}$ If $E_{0}$ coincides with $E_{1}$, then there is no incentive for individuals to become skilled workers through costly training. In Figure 1, point $E_{0}$ lies to the left of $E_{1}$ to illustrate that the wage of skilled always exceeds the wage of unskilled workers.

It is obvious from Figure 1 that an increase in the price of innovation $\mathrm{S}$ raises the wage of skilled workers and reduces the wage of unskilled workers by shifting $B\left(w_{L}, w_{H}\right)=S$ upward, if and only if $R \& D$ is the skill intensive activity (i.e. curve $B(\cdot)=S$ is flatter than curve $A(\cdot)=1$ ). The increase in the relative wage of skilled workers reduces $\theta_{0}$ and increases the relative abundance of skilled labor and the proportion of population that chooses to become skilled 
workers. Therefore, an increase in the price of innovation increases wage inequality and results in across-the-board skill upgrading if and only if R\&D is the skill intensive activity.

The Schumpeterian version of the Samuelson-Stolper mechanism provides a novel explanation for the factor "bias" of technological progress. Whether an acceleration of acrossthe-board technological change (caused by an increase in the reward to innovation) is skilled or unskilled-worker biased depends precisely on the relative intensities of the two activities. Although unskilled-labor saving technological change is a sufficient condition that might have generated the observed changes in the relative wages, the above analysis suggests that it is hardly a necessary one. Trade liberalization exercises an upward pressure on $\mathrm{S}$ through its positive impact on the instantaneous profits of all quality leaders. However, $\mathrm{S}$ is an endogenous variable that depends on virtually all parameters of the model in addition to R\&D difficulty $X$ and global R\&D investment. This is the reason why the above results are stated as a lemma instead of a theorem. The following subsection introduces the factor-market-equilibrium conditions which close the model and allow us to analyze the properties of the steady-state equilibrium.

\subsection{Factor Markets}

We assume wage flexibility and perfect mobility of factors of production across industries and activities. These assumptions imply that the supply and demand for skilled and unskilled labor are equalized at each instant in time. Because both countries are identical in all respects, we concentrate on the derivation of equilibrium in the Home country. Equation (8) provides the supply of unskilled labor, whereas the demand for it consists of two components: unskilled labor employed in R\&D and unskilled labor employed in manufacturing of final products. We consider the determination of each component of demand below.

The demand for unskilled R\&D labor targeting industry $\omega$ at time $t$ is derived from (24) through Shephard's lemma and equals $B_{L}\left(w_{L}, w_{H}\right) X(\omega, t) I(\omega, t)$ where $B_{L} X=\left(\partial B / \partial w_{L}\right) X$ is the 
unskilled labor requirement per unit of R\&D services, and $I=\underset{i}{\Sigma I_{i}}$ is industry-wide R\&D investment. Because $R \& D$ races occur in all industries and the measure of all these identical industries equals one, $\mathrm{B}_{\mathrm{L}} \mathrm{XI}$ is also the economy-wide demand for unskilled labor employed by firms engaged in R\&D.

By differentiating (10) with respect to $w_{L}$ one obtains $A_{L}\left(w_{L}, w_{H}\right) Q(\omega, t)$ which equals the demand for unskilled labor in manufacturing of industry $\omega$ at time t. Expression $A_{L}=\partial A / \partial w_{L}$ is the unskilled labor requirement per unit of final output. The assumption of identical countries implies that 50 percent of world's quality leaders are Home firms and 50 percent are Foreign firms. In industries with a Home quality leader (exporting industries) total output produced equals $Q_{f}+Q_{l}+Q_{l}^{*}$, where $Q_{f}$ is output produced by Home followers, $Q_{l}$ is the leader's output sold at Home and $Q_{i}{ }^{\top}$ is the leader's output sold to foreign consumers (exports). In industries with a foreign leader, only protected Home followers produce and compete against imports. In Home import-competing industries production equals $Q_{f}^{*}$ given the structural symmetry between the two countries. Therefore, the total output produced in each country is

$$
q=1 / 2\left(Q_{f}+Q_{l}+Q_{i}\right)+1 / 2 Q_{f}^{*}=\frac{c(t) N(t)[2(2 \lambda-1)+\tau(\lambda-1)]}{2 \lambda^{2}},
$$

where $q$ is the "average" quantity of final output produced in each industry. The economy-wide demand for unskilled labor in manufacturing is therefore $A_{L}\left(w_{L}, w_{H}\right) q$, and the full-employment condition of unskilled labor is

$$
\theta_{0} N(t)=A_{L}\left(w_{L}, w_{H}\right) q+B_{L}\left(w_{L}, w_{H}\right) X I
$$

Equation (9) provides the supply of skilled labor, and its demand is derived by the same procedure as the demand for unskilled labor, the only difference being that the industry-wide cost functions are differentiated with respect to the wage of unskilled labor. Therefore the fullemployment condition of skilled labor is

$$
\frac{\left[1-\left(\theta_{0}\right)^{2}\right]}{2} \phi N(t)=A_{H}\left(w_{L}, w_{H}\right) q+B_{H}\left(w_{L}, w_{H}\right) X I .
$$


Equations (30) and (31) constitute the basic conditions that determine the long-run equilibrium of the model.

\subsection{Steady-State Equilibrium}

Appendix B establishes formally the existence of a unique balanced-growth equilibrium where consumption per capita $c, R \& D$ difficulty per capita $x=X N, R \& D$ investment $I=I^{*}$, and wages $w_{L}, w_{H}$ are all constant over time. Constant steady-state consumption per capita implies $r(t)=\rho$. Constant wages and $R \& D$ difficulty per capita imply constant $\theta_{0}$ and $\dot{v} / v=\dot{X} / X=n$ (see equation (28)). Straightforward substitutions provide the following expression for q:

$$
q=B\left(w_{L}, w_{H}\right)(\rho+2 I-n) \psi(\tau) X
$$

where $2 \mathrm{I}=\mathrm{I}+\mathrm{I}^{*}$ due to structural symmetry between the two countries, and where

$$
\Psi(\tau)=\frac{q}{\pi}=\frac{[2(2 \lambda-1)+\tau(\lambda-1)]}{2\left[\frac{(\lambda-1-\tau)^{2}}{(1+\tau)}+(\lambda-1)^{2}\right]}
$$

is the inverse of instantaneous profits per unit of average final output and depends only on the level of protection and the size of innovations. ${ }^{22}$ It is obvious from (33) that an increase in protection increases $\psi(\tau)$.

Equations (7) and (11) define implicitly each wage as a function of $\theta_{0}$ with $d w_{L} / d \theta_{0}>0$ and $d w_{\mathrm{H}} / \mathrm{d} \theta_{0}<0$. There is a positive relationship between an increase in the wage of unskilled labor and the fraction of population that chooses to remain unskilled. The opposite is true between the wage of skilled workers and $\theta_{0}$. Substituting (32) into the full-employment of labor conditions (30) and (31) and dividing both sides of each equation by $N(t)$ yields

$$
\begin{gathered}
\theta_{0}=A_{\mathrm{L}}\left(\theta_{0}\right) B\left(\theta_{0}\right) \Psi(\tau)(\rho+2 I-n) x+B_{L}\left(\theta_{0}\right) I x \\
\frac{\left[1-\left(\theta_{0}\right)^{2}\right] \phi}{2}=A_{H}\left(\theta_{0}\right) B\left(\theta_{0}\right) \Psi(\tau)(\rho+2 I-n) x+B_{H}\left(\theta_{0}\right) I x
\end{gathered}
$$

where the unit resource requirements and $B(\cdot)=S$ depend on $\theta_{0}$ through $w_{L}$ and $w_{H} \cdot$ We have managed to reduce the model to a system of two equations in three unknowns, $\theta_{0}, x$, and $I$. The 
third equation is provided by whether the TEG or the PEG specification of R\&D difficulty is used.

Consider the TEG model first, and notice that equation (25) yields $\dot{\mathrm{X}} / \mathrm{X}=\mathrm{n}=2 \mu \mathrm{I}$. Therefore the steady-state level of R\&D investment I is completely determined by the exogenous rate of population growth and the $R \& D$ difficulty growth parameter. If $R \& D$ does not become more difficult over time (i.e. $\mu=0$ ), then there is no steady-state equilibrium with finite $R \& D$ investment.

Figure 2 illustrates the unique steady-state equilibrium of the model under the TEG specification. The vertical line measures the proportion of population that remain unskilled workers $\theta_{0}$, and the horizontal line measures the R\&D difficulty per capita $x$. The graph of equation (34) is the locus of $\mathrm{x}$ and $\theta_{0}$ that are consistent with full employment of unskilled labor, where $I=n / 2 \mu$. This graph is upward sloping and starts at the origin because $x=\theta_{0}=0$ satisfy the equation. An increase in $\theta_{0}$, induced by an increase in the relative wage of unskilled workers, reduces the demand for unskilled labor and increases its supply for any fixed level of $\mathrm{x}$. Thus the LHS of (34) exceeds the RHS and an increase in $\mathrm{x}$ is required to balance both sides of equation (34) and to restore equilibrium in the unskilled labor market.

The graph of equation (35), which corresponds to the full-employment condition of skilled labor, starts at $\theta_{0}=1$ and is downward sloping. An increase in $\theta_{0}$, caused by a reduction in the relative wage of skilled workers, increases the demand for skilled labor and reduces itś supply for any given value of $x$. A reduction in $x$ is required to reduce the RHS of (35) and restore equilibrium in the skilled labor market. The unique intersection of (34) and (35) determines the steady-state values of $\mathrm{x}$ and $\theta_{0} \in(0,1)$ in the TEG specification of the model. A sufficient but hardly necessary condition that guarantees the existence of a unique steady-state equilibrium in the TEG model is that 


$$
\lim _{\theta_{0}-\theta^{*}} g\left(\theta_{0}\right)<\infty \text {, where } g\left(\theta_{0}\right)=\frac{\theta_{0}+\sigma\left[B_{H}\left(\theta_{0}\right) / B_{L}\left(\theta_{0}\right)\right]}{\theta_{0}+\sigma\left[A_{H}\left(\theta_{0}\right) / A_{L}\left(\theta_{0}\right)\right]}
$$

This condition is satisfied for Cobb-Douglas production functions and for the class of CES functions where both inputs are essential for production.

Figure 3 illustrates the unique steady-state equilibrium in the PEG model. Assumption (26) fixes the value of R\&D difficulty per capita $x=k$. Because the RHS of (34) and (35) are increasing in R\&D investment I, the graph of (34) is upward sloping and the graph of (35) is downward sloping as in the case of the TEG specification. These curves intersect the vertical axis above the origin and below point $\theta_{0}=1$. Condition (36) and a low value of $k$ (i.e. low level of R\&D difficulty per capita) guarantee the existence of a unique steady-state equilibrium in the PEG model.

\subsection{Long-run Growth}

The unique steady-state equilibrium in both the TEG and PEG models exhibits constant growth rate of each consumer's utility caused by the perpetual introduction of higher quality products. By substituting for consumer demand $(c(t) / \lambda)$ into a representative consumer's static utility function, we obtain $\log u(t)=\log c(t)-\log \lambda+\int_{0}^{1} \log \lambda^{j(\omega, t)} d \omega$, where $j(\omega, t)$ is the number of quality improvements in industry $\omega$ at time t. The integral in this expression grows over time in the steady-state equilibrium as new products are introduced. The value of this integral equals $2 \mathrm{It} \log \lambda$, where $\int_{0}^{\mathrm{t}} \mathrm{j}(\omega, \mathrm{t}) \mathrm{d} \omega=2 \mathrm{It}$ equals the expected value of $\mathrm{j}(\omega, \mathrm{t})$ and $2 \mathrm{I}$ is the steady-state intensity of the Poisson process that governs the arrival of innovations. Thus. in the steady-state equilibrium, each consumer's utility grows at the deterministic rate

$$
\mathrm{g}_{\mathrm{u}}=\frac{\dot{\mathrm{u}}(\mathrm{t})}{\mathrm{u}(\mathrm{t})}=2 \mathrm{l} \log \lambda
$$

In the TEG model, the R\&D intensity I depends only on parameters $\mathrm{n}$ and $\mu$, and therefore trade liberalization has only transitional growth effects. In the PEG model, any shift in either or both curves of Figure 3 generates long-run growth effects. In both models, positive 
population growth does not drive the long-run R\&D intensity and per capita growth to infinity.

\section{Trade Liberalization, Relative Wages, and Economic Growth}

The main result of the paper is established by the following theorem:

Theorem 1: In the absence of factor intensity reversals, a permanent increase in global trade liberalization caused by a reduction in $\tau$.

(i) permanently reduces the wage of unskilled labor $w_{L}$ and increases the wage of skilled labor $w_{H}$ if and only if $R \& D$ investment is the skill intensive activity $\left(B_{H} / B_{L}>A_{H} / A_{\nu}\right)$;

(ii) permanently decreases the fraction of the population that chooses to remain unskilled $\theta_{0}$ if and only if $R \& D$ investment is the skill intensive activity $\left(B_{H} / B_{L}>A_{H} / A_{\nu}\right)$;

(iii) temporarily increases the global rate of technological progress 21 , but has no effect on the long-run growth rate $g_{u}$ in the TEG version of the model;

(iv) permanently increases both the global rate of technological progress $2 I$ and the long-run growth rate $g_{u}$ in the PEG version of model.

Proof: See Appendix A.

We are now in the position to state intuitively the general equilibrium effects of global trade liberalization. Trade liberalization increases the profitability of new-product innovations for any given levels of R\&D difficulty and $R \& D$ investment. It also increases the openness of the global economy measured by the share of trade in aggregate consumption (Proposition 1 ). The increase in $R \& D$ profitability increases the "price" of innovation $S$ at the initial values of I and $\mathrm{x}$. An increase in $\mathrm{S}$ induces resources to move from manufacturing of final goods to $R \& D$ investment and increases the pace of global technological progress temporarily or permanently depending on whether the TEG or the PEG specification is used. These indirect generalequilibrium effects on $I$ and $x$ do not reverse the initial increase in the price of innovation which remains higher than its initial value. 
The long-run increase in S affects relative wages and the supplies of unskilled and skilled labor through the Schumpeter-Stolper-Samuelson mechanism. If R\&D is the skill intensive activity, an increase in the profitability of innovation captured by $S$ worsens the wage income distribution by reducing the relative wage of unskilled workers and by increasing the wage of skilled labor. It also causes a reduction in the fraction of population that remains unskilled, $\theta_{0}$. This change can account for skill upgrading measured by the number of skilled workers as a fraction of total (manufacturing and R\&D) employment in each industry (see footnote 3). By construction, industries are structurally identical and so are the two countries. Therefore skill upgrading and resource changes occur only within each industry, and all the above-mentioned effects of trade liberalization are global. Finally, it is worth emphasizing that domestic relative prices remain unaffected throughout this process (Proposition 1). Consequently, the seven stylized facts during the 1980 s are consistent with a North-North trade-liberalization scenario that has been rejected by many economists.

Exogenous technical change has been accepted as a "residual" explanation of the seven stylized facts mentioned in the introduction. (See footnotes 10 and 11). In the context of the present model, an exogenous increase in $\lambda$ captures a permanent increase in the size of innovations that corresponds to a demand-based acceleration of global technological change. In addition, a reduction in $\mathrm{k}$ in the PEG model corresponds to an exogenous permanent technical change in the provision of R\&D services. It is straightforward to establish that an increase in $\lambda$ or a reduction in $\mathrm{k}$ increases the profitability of $\mathrm{R} \& \mathrm{D}$ and triggers the Schumpeter-StolperSamuelson mechanism that affects factor markets in exactly the same manner as a reduction in the common tariff. ${ }^{23}$ However, exogenous technological change caused by an increase in $\lambda$. increases the relative price of domestic goods and decreases economic openness (Proposition 1), contrary to $\mathrm{SF}(5)$ and $\mathrm{SF}(6)$. Similarly, a reduction in $\mathrm{k}$ leaves both relative domestic prices and 
the openness of each economy intact, contrary to $S F(5) \cdot{ }^{24}$ Consequently, technical change alone represents an unlikely explanation for all seven stylized facts that characterized the global economy in the 1980 s, although in conjunction with trade liberalization technical change might have amplified some observed changes.

\section{Conclusions}

The analysis of this paper challenges several prevailing explanations for the decline of the relative wage of unskilled workers during the 1980 s. Many economists have excluded trade liberalization as the cause of this change based on the fact that domestic relative prices have not declined. Other economists have adopted the view that competition from the South must have been responsible for the decline in the relative wage of unskilled workers (e.g. Wood (1995)).

A major insight of our analysis is that in imperfectly competitive markets, where Schumpeterian competition determines the pace of technological progress, changes in relative prices represent only one channel that links wages to trade liberalization. In these markets, expected discounted profits of innovating play the same role as the domestic relative price in the conventional Heckscher-Ohlin-Samuelson model. Therefore, even if relative prices remain unaffected by trade liberalization (as in this model), a reduction in global tariffs that increases the profitability of $R \& D$ generates changes in relative wages whose signs depend precisely on the Stolper-Samuelson condition of intensity rankings between $R \& D$ and manufacturing activities.

- We appropriately call the relationship between the relative price of innovation and the returns to factors of production the Schumpeter-Stolper-Samuelson mechanism.

Another new insight of the analysis is that unskilled-labor biased technological change is not a necessary condition for a reduction of the relative wage of unskilled workers. Any increase in the profitability of innovation that results in higher R\&D investment and acceleration of technological change can affect adversely the wage income of unskilled workers if and only if 
$R \& D$ is skill intensive relative to manufacturing of final goods. The structure of the model supports the view that a North-North trade explanation of wage changes cannot be excluded by the evidence. Introducing asymmetries in country size or in the distribution of abilities across countries could allow the model to address the nature of North-South trade effects on wages. ${ }^{25}$

We are anxious to point out that our analysis does not advocate protection as a remedy for raising the standards of living of unskilled workers. In the context of our model, protection would increase the wage of unskilled workers (if R\&D is skill intensive), but this is a level (as opposed to growth) effect. Protection slows temporarily (in the TEG model) or permanently (in the PEG model) the growth in the standards of living of all workers measured by the growth in utility. In addition, protection retards the formation of human capital by increasing the fraction of population that remains unskilled in the long run. Therefore, the income distribution leveltype benefits of protection should be weighted against the intertemporal costs of lower growth in living standards and lower human capital formation. Welfare analysis can provide some policy guidelines, but the transitional dynamics of the model are complicated, and we suspect that formal welfare analysis would be theoretically intractable. 


\section{Endnotes}

1. Deardoff and Hakura (1994), Burtless (1995), and Richardson (1995) provide excellent overviews of these studies and the evidence.

2. The real hourly wage of male workers with 12 years of schooling dropped by 20 percent (Freeman (1995)), and wage earnings differentials between high-school and college graduates in the U.S. rose by more than 10 percent (Berman, Bound and Griliches (1994)).

3. Employment of production workers in U.S. manufacturing dropped by about 15 percent, whereas the employment of non-production workers increased by 3 percent (Berman et al. (1994)). Employment of engineers in U.S. manufacturing increased by 55 percent, and employment of scientists increased by 12 percent. (Shatz (1996)).

4. Intraindustry (as opposed to interindustry) skill upgrading accounts for about 0.40 out of 0.55 share increase per year in U.S. manufacturing (Berman et al. (1994)).

5. Between 1979-1988 multifactor productivity growth increased by 40 percent relative to productivity growth in the previous two decades. $R \& D$ expenditure as a fraction of manufacturing shipments also experienced a sizeable increase (Berman et al. (1994)). When adjusted for skill level, total factor productivity growth has been virtually identical across industries (Sachs and Shatz (1994)).

6. Trade as a share of U.S. manufacturing shipments increased by about 30 percent during the 1980s with imports accounting for most of the increase (Berman et al. (1994)). Trade accounted for about 3 percent of U.S. GDP in 1970 compared to 10-12 percent in the mid 1990s (Richardson (1995)).

7. There is no unanimous agreement among economists on the behavior of domestic relative prices during the 1980s. Richardson (1995) reports that Lawrence and Slaughter (1993) found unchanged relative prices, Sachs and Shatz (1994) found a small decline in relative prices, whereas Feenstra and Hanson (1994) found increases in domestic prices relative to foreign ones. We argue that trade liberalization can affect the wages independently of changes in relative prices, and therefore $\mathrm{SF}(6)$ expresses the view of international economists that have argued against a trade explanation for the decline in unskilled wages.

8. Richardson (1995, footnote 1) cites several studies that have documented the decline in relative wages of unskilled workers in several advanced and less developed countries. In most of continental Europe, where labor markets are characterized by wage rigidities, the reduced demand for low-skilled workers manifested itself in the form of increased unemployment. (See the Economist, September 28. 1996, p. 24, and Davis (1996a)).

9. Borjas and Ramey (1994), for example, report a significant negative correlation between the relative wage of unskilled workers and net imports of durable goods as a percentage of GNP based on time-series evidence from the U.S.

10. According to Deardoff and Hakura (1994), "those studies that have related the changes in factor prices to, say, the volume of trade cannot therefore be said to have been necessarily applying the Stolper-Samuelson theorem." Bhagwati (1995) reflects the same view when he 
states "Thus, I find it difficult to accept the argument... that almost all "quantity" data point towards trade as the source of the problem and that it is only "prices" that do not conform. To say that is to say that, in a production of Hamlet, only the Prince was missing, all else was fine!".

11. Berman et al. (1994), Krugman and Lawrence (1994), Bhagwati (1995) and Davis (1996b) among others have proposed this explanation. The Economist (September 28, 1996, page 28) reports that economists polled at a 1995 New York Federal Reserve conference concured by a margin of four to one that technology was more important than trade in explaining widening wage inequality.

12. We model product instead of process innovation for several reasons. First, process and product innovations are isomorphic in models of endogenous technological progress. Second, Scherer (1983) reports that about 75 percent of company financed R\&D aims at product innovations. Third, empirical studies of wage earnings inequality have emphasized the role of computerization in reducing the relative demand for unskilled labor. Most innovations in the computer industry take the form of better products.

13. During the 1980 's many U.S. industries faced import competition from higher quality products produced abroad (e.g. semiconductors, automobiles, steel, machine tools). In all these industries technological competition between U.S. firms and their foreign counterparts resulted in the deterioration of U.S. international competitiveness. All these industries experienced changes in trade barriers during the 1980 s.

14. The assumption that all family members have identical abilities raises the standard question of how families with skilled workers finance consumption at time zero. The existence of educational loans, or the assumption that abilities are uniformly distributed within each family resolve this issue without altering the properties of the model.

15. Differentiating (4) with respect to time yields the standard flow budget constraint $\dot{z}_{\theta}=w_{\theta}+r z_{\theta}-c_{\theta}-n z_{\theta}$, where $z_{\theta}$ and $w_{\theta}$ denote the per capita financial assets and the wage income of a household member respectively.

16. Setting $\mathrm{D}-\infty$ yields the special case of infinitely lived individuals where $\sigma=\mathrm{e}^{\rho \mathrm{T}}>1$ and $\psi=$ $\mathrm{e}^{-\mathrm{nT}}<1$. Equations (7), (8) and (9) are not affected qualitatively, and the results of the paper hold in this case as well.

17. Segerstrom, Anant and Dinopoulos (1990) used a similar assumption in a model of NorthSouth trade and growth. This assumption implies strong knowledge spillovers within each industry and across countries, and it is consistent with the spirit of the Heckscher-OhlinSamuelson model which assumes identical technologies across countries. Dinopoulos and Segerstrom (1996) assumed that each quality leader receives an infinite-duration patent to analyze the dynamic effects of contingent tariff protection.

18. Equation (24) is the cost function associated with the following production function of $R \& D$ services: $I_{i}(\omega, t)=F_{B}\left(L_{i}, H_{i}\right) / X$, where $F_{B}(\cdot)$ is a constant returns to scale production function and $L_{i}(\omega, t), H_{i}(\omega, t), X(\omega, t)$ are the amount of unskilled labor, the amount of skilled labor, and $R \& D$ difficulty in industry $\omega$ at time $t$. 
19. Segerstrom (1995) has proposed this formulation of R\&D difficulty.

20. Dinopoulos and Thompson (1996) have provided micro-foundations for (26) in a model of growth through variety accumulation.

21. If curve $A\left(w_{L}, w_{H}\right)=1$ intersects the vertical axis (as in the case of a CES production function), then there exists a value of $S<\infty$ such that $w_{L}=0$ and $\theta_{0}=0$.

22. Equation (32) is derived from (28) as follows: Substitute $\pi$ from (22) into the steady-state value of $v(t)=\pi /(\rho+2 I-n)$ (see (27)). Solving for consumption per capita $c$ and substituting the resulting expression in (29) provides (32).

23. Parameter $\lambda$ enters the model only through function $\psi(\tau, \lambda)$ which is decreasing in $\lambda$. In the PEG model, the RHS of (34) and (35) increase in $x=k$. Therefore theorem 1 applies to an increase in $\lambda$ or a reduction in $k$ as well. It is worth noting that because $\dot{x} / \mathbf{x}=n$ in the TEG model, a change in $\mu$ is not equivalent to exogenous technical change in $R \& D$, but reflects changes in the long-run value of R\&D investment.

24. We also analyzed the effects of exogenous technological change that increases the relative demand for skilled labor in manufacturing (i.e. an exogenous increase in the skill intensity of manufacturing for any given value of the relative wage ratio). This type of technical change has been associated with increased use of computers in manufacturing. In the case of CobbDouglas manufacturing and $R \& D$ production functions, an exogenous increase in skill intensity of manufacturing increases wage inequality, but it is also likely to slow technological change if R\&D mainly employs skilled workers and most of the labor force is unskilled. In addition, this type of exogenous technical change leaves the openness of the economy unaffected contrary to SF5.

25. Although a North-North trade explanation is consistent with the seven stylized facts in the 1980s, other studies have provided alternative trade-based explanations for the decline in the relative wage of unskilled workers. Davis (1996a, 1996b) has examined the impact of trade and technology in a two-country global economy with one country experiencing unemployment based on an institutionally fixed minimum wage for unskilled workers. Feenstra and Hanson (1994) have analyzed the impact of foreign investment and outsourcing on relative wages in a model of differentiated intermediate products. Bhagwati (1995) has proposed a North-North trade explanation based on shifts in international competitiveness that are causing higher labor turnover and unemployment among unskilled workers. Richardson (1995) has also emphasized the dichotomy between consumption and investment goods in a model of trade, technology and relative wages. The present paper contributes to this literature by focusing on dynamic aspects of international competition and by highlighting the Schumpeter-Stolper-Samuelson mechanism that links trade volumes to relative wages independently of relative commodity prices. 


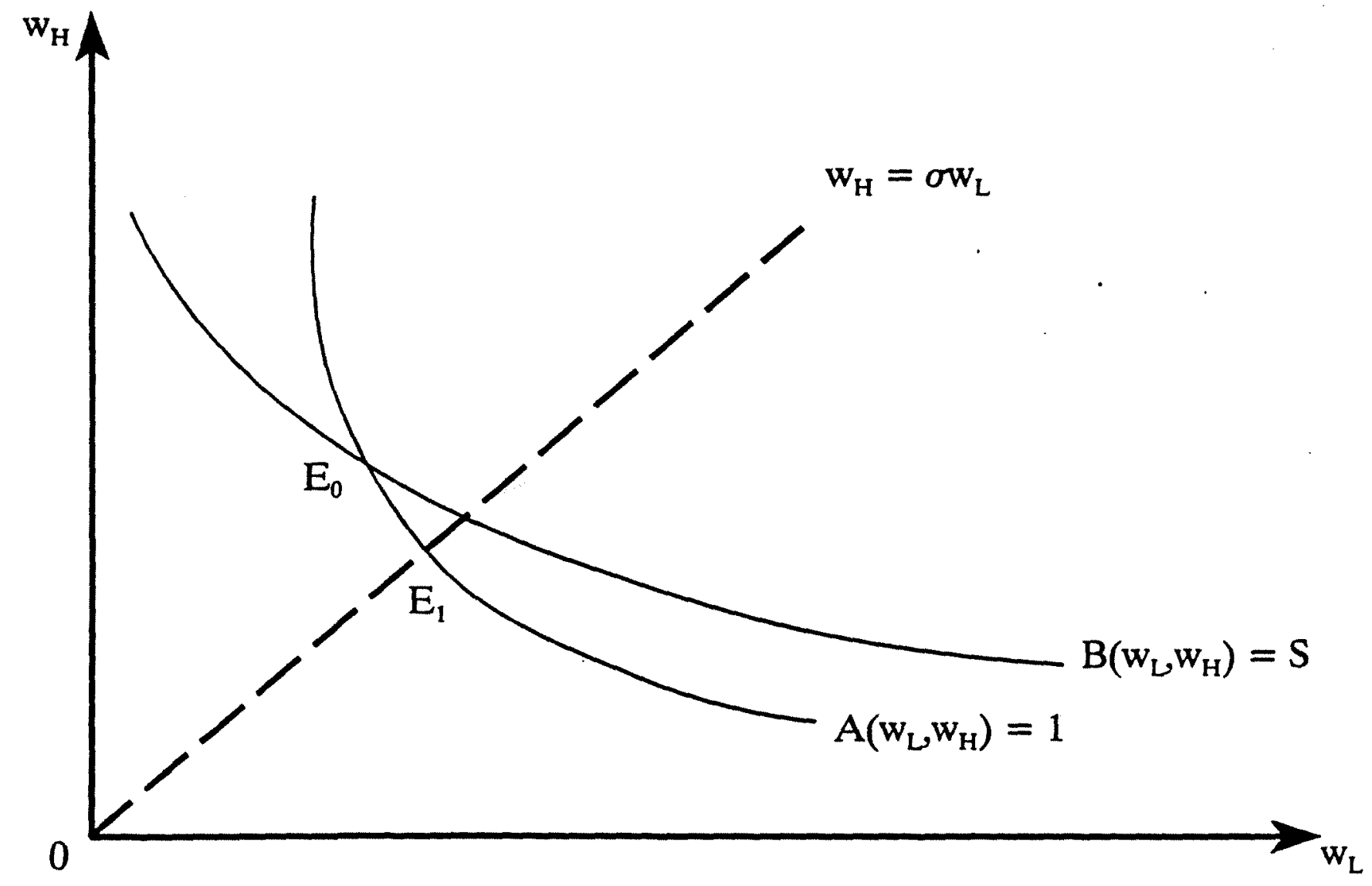

Figure 1: Equilibrium wages with $R \& D$ being the skill-intensive activity 


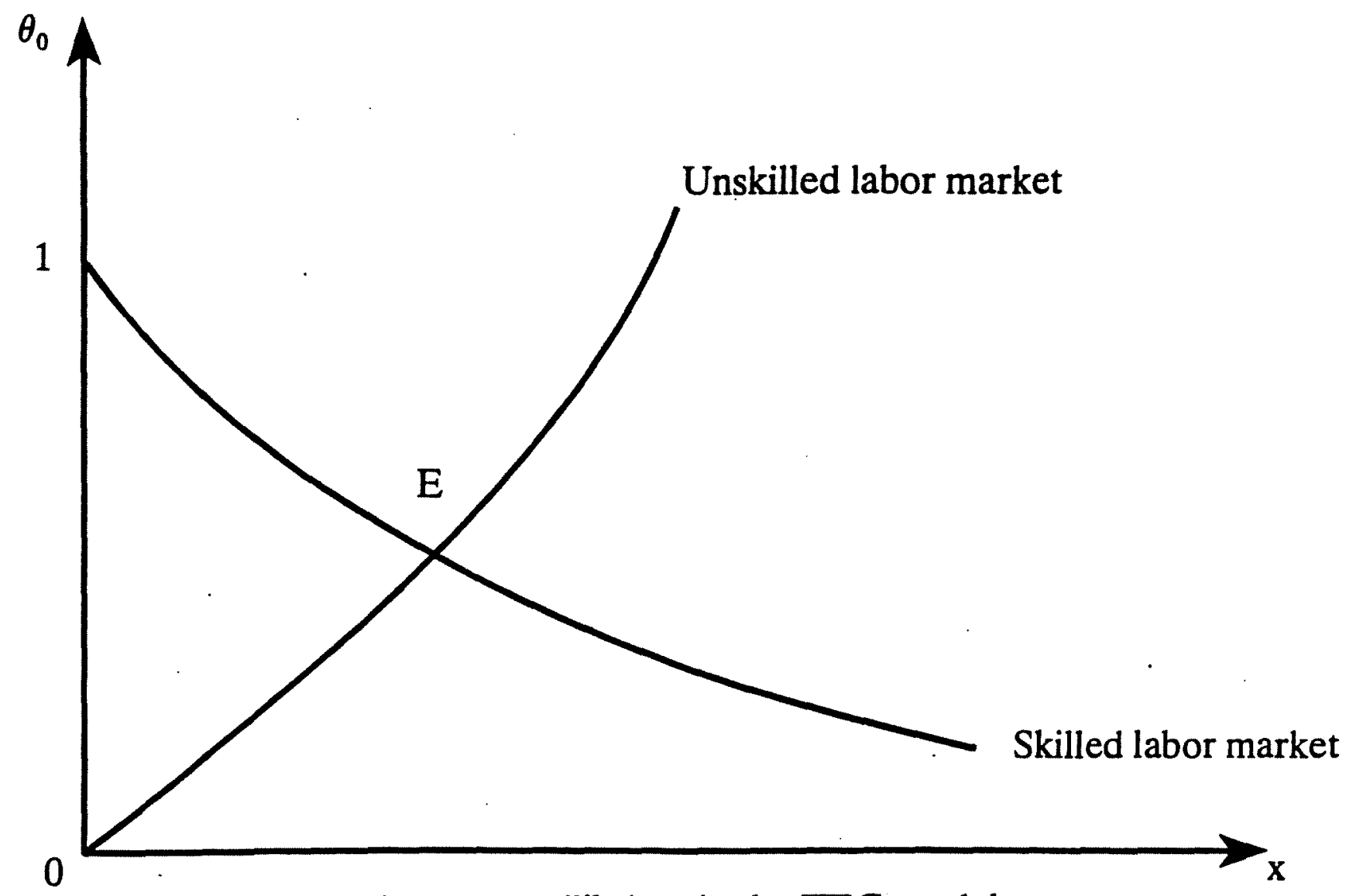

Figure 2: Steady-state equilibrium in the TEG model

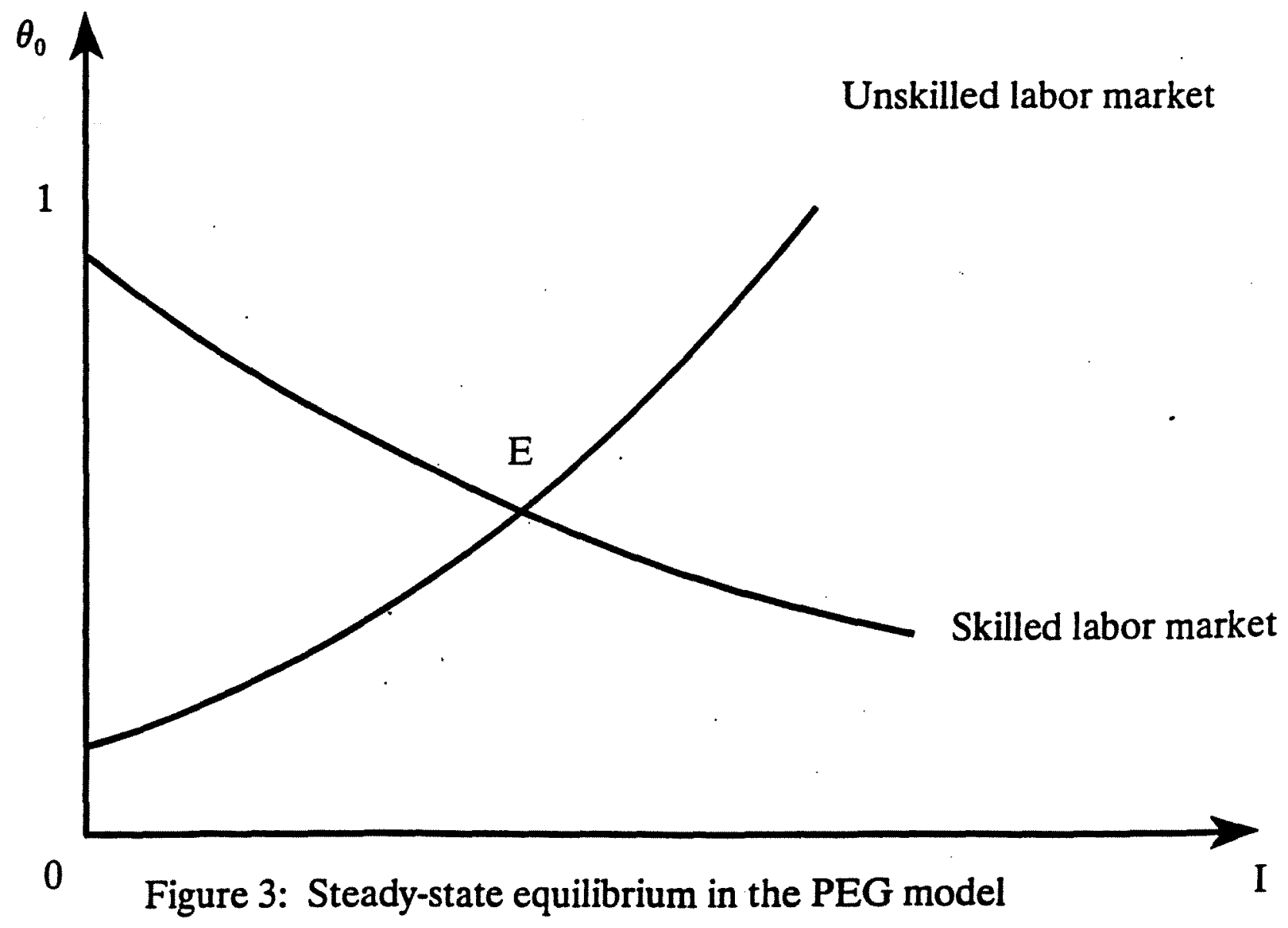




\section{APPENDIX A}

Proof of Lemma 1: Shephard's lemma yields the skill intensities in R\&D investment and manufacturing of final products: $\left(\partial F_{\mathrm{L}} / \partial w_{H}\right) /\left(\partial F_{l} / \partial w_{L}\right)=B_{H} / B_{L}$ and $\left(\partial F_{Q} / \partial w_{H}\right) /\left(\partial F_{Q} / \partial w_{L}\right)=A_{H} / A_{L}$ respectively, where $F_{1}(\cdot)$ is given by $(24)$ and $F_{Q}(\cdot)$ is given by $(10)$. Consequently, $R \& D$ is the skill intensive activity if and only if $B_{H} / B_{L}>A_{H} / A_{L}$.

Totally differentiating equations (11) and (28) and solving for the change in each relative wage with respect to a change in the price of innovation yields

$$
\begin{aligned}
& \frac{d w_{L}}{d S}=\frac{-A_{H}}{B_{H} A_{L}-A_{H} B_{L}} \\
& \frac{d w_{H}}{d S}=\frac{A_{L}}{B_{H} A_{L}-A_{H} B_{L}}
\end{aligned}
$$

The denominator in (A1) and (A2) is positive (negative) if $R \& D$ (manufacturing) is skill intensive. The absence of factor intensity reversals guarantees that the sign of the denominator is the same for all values of the relative wage ratio. This completes the proof of part (i).

Differentiate equation (7) totally and substitute (A1) and (A2) to obtain

$$
\frac{d \theta_{0}}{d S}=\frac{\sigma}{w_{H}} \frac{d w_{L}}{d S}-\frac{\sigma w_{L}}{w_{H}^{2}} \frac{d w_{H}}{d S}=-\frac{\sigma}{w_{H}^{2}\left(B_{H} A_{L}-A_{H} B_{L}\right)},
$$

where $A=A_{L} w_{L}+A_{H} w_{H}=1$ has been used as well. This completes the proof of part (ii).

Proof of Theorem 1: Because the tariff enters (34) and (35) through function $\psi(\tau)$, it is sufficient to analyze how each curve shifts as a result of trade liberalization that decreases $\psi$ (see (33)). A reduction in $\psi$ increases the value of $x$ (or I) for any given value of $\theta_{0}$ in both equations (34) and (35). Therefore both curves move to the right as a result of trade liberalization.

Differentiate (34) and (35) with respect to $\psi$ and $x$ holding $\theta_{0}$ constant to obtain: 


$$
\begin{aligned}
& \left.\frac{-d x}{d \Psi}\right|_{(34)}=\frac{B(\rho+n / \mu-n) x}{B \Psi(\rho+n / \mu-n)+\frac{B_{L} n}{A_{L} 2 \mu}} \\
& \left.\frac{-d x}{d \Psi}\right|_{(35)}=\frac{B(\rho+n / \mu-n) x}{B \Psi(\rho+n / \mu-n)+\frac{B_{H} n}{A_{H} 2 \mu}} .
\end{aligned}
$$

It is obvious from inspection of (A4) and (A5) that only the last term in each denominator differs. Therefore, the RHS of (A4) is larger than the RHS of (A5) if and only if $B_{L} / A_{L}<B_{H} / A_{H}$. Because the RHS of (34) and (35) are increasing and linear in I, one can obtain the same result for the PEG specification. Thus, in both models a reduction in the common tariff reduces $\theta_{0}$ if and only if R\&D is the skill intensive activity.

Totally differentiating equations (7) and (11) yields

$$
\frac{d w_{L}}{d \theta_{0}}=\frac{A_{H} w_{H} w_{L}}{\theta_{0}}>0 ; \frac{d w_{H}}{d \theta_{0}}=-\frac{A_{L} w_{H} w_{L}}{\theta_{0}}<0 .
$$

Expressions (A6) together with the result that trade liberalization reduces $\theta_{0}$ if and only if $R \& D$ is the skill intensive activity prove formally parts (i) and (ii) of Theorem 1. Parts (iii) and (iv) follow from the result that trade liberalization shifts both curves in Figures 2 and 3 to the right and results in a permanent increase in $x$ or I depending on whether the TEG or the PEG specification is used. In the case of the TEG model, a higher long-run value of $x=X / N$ implies that $\mathrm{X}$ has to grow faster than $\mathrm{N}$ temporarily, and therefore I has to increase temporarily as well based on equation (25). 


\title{
A SCHUMPETERIAN MODEL OF PROTECTION AND RELATIVE WAGES
}

\author{
by \\ Elias Dinopoulos \\ and \\ Paul Segerstrom \\ (University of Florida) \\ (Michigan State University)
}

\begin{abstract}
APPENDIX B
Family's optimization problem: The Family's optimization problem can be solved in four steps. Omitting subscript $\theta$ for notational simplicity, consider the allocation of expenditure among products within an industry. Products are identical when adjusted for quality, and therefore consumers buy only the products with the lowest quality adjusted price. In the present context, only the state-of-the art quality product and the product one step below will be purchased at equilibrium. The second step involves the allocation of consumption per capita $\mathrm{c}(\mathrm{s})$ across all available products which yields the following maximization problem:

$$
\max _{q} \int_{0}^{1} \log \left[\lambda^{j(\omega, s)} q(\omega, s)\right] d \omega
$$
\end{abstract}

subject to

$$
c(s)=\int_{0}^{1}[p(\omega, s) q(\omega, s)] d \omega,
$$

where $j(\omega, s)$ equals the number of innovations in industry $\omega$ at time s. The solution to (B1) yields

$$
q(\omega, s)=\frac{c(s)}{p(\omega, s)} .
$$

The next step of the family's optimization problem is to maximize (1) subject to the evolution of wealth (4). Substituting (B2) into (2) and taking into account that the evolution of innovation $j(\omega, s)$ and prices $p(\omega, s)$ are taken as given, the Hamiltonian for the intertemporal maximization problem is

$$
H=\left[e^{-\rho s} e^{n s} \log c+l(s)\left[c e^{n s} e^{-[R(s)-R(t)]}\right] N_{0}\right.
$$


where $\mathrm{l}(\mathrm{s})$ is the costate variable. Noting that the costate equation is $\partial \mathrm{l}(\mathrm{s}) / \partial \mathrm{s}=0$, and differentiating the first-order condition $\partial H / \partial \mathrm{c}=0$ with respect to time s yields

$$
\frac{\dot{c}(s)}{c(s)}=r(s)-\rho .
$$

Equation (B3) can be solved for consumption $\mathrm{c}(\mathrm{s})$ :

$$
c(s)=c(t) e^{-p(s-t)} e^{[R(s)-R(t)]} \text {. }
$$

Substituting (B4) into the intertemporal budget constraint (4) yields

$$
c(t)=\frac{[W(t)+Z(t)](\rho-n)}{N(t)},
$$

which states that consumption per capita is proportional to total wealth $W(t)+Z(t)$. Because, at time $t$ the value of $Z(t)$ depends on past decisions, the higher is the discounted wage income $W(t)$, the higher is the family's consumption per capita and utility. Therefore, the decision to remain unskilled or to become a skilled worker depends only on maximization of each member's discounted wage income from time $t$ (when a member is born) to time $t+D$ (when that member dies)). Thus, an individual with ability $\theta$ born at time $t$ becomes a skilled worker if and only if

$$
\int_{t}^{t+D} e^{-[R(s)-R(t)]} w_{L}(s) d s<\int_{t+T}^{t+D} e^{-[R(s)-R(t)]} \theta_{w_{H}}(s) d s
$$

Existence of a unique long-run equilibrium: First, we establish that the graph of the full employment of unskilled workers condition is upward sloping and that the graph of the full employment of skilled workers condition is downward sloping. Second, we show that, under reasonable restrictions on the model's parameters, the downward sloping curve has a higher vertical intercept than the upward sloping curve as shown in Figures 2 and $3 .$.

Equations (7) and (11) define $w_{L}$ and $w_{H}$ as functions of $\theta_{0}$. Totally differentiating these two equations yields

$$
\frac{d w_{L}}{d \theta_{0}}=\frac{A_{H} w_{H} w_{L}}{\theta_{0}}>0 ; \frac{d w_{\dot{H}}}{d \theta_{0}}=-\frac{A_{L} w_{H} w_{L}}{\theta_{0}}<0 .
$$

The cross partial derivatives of unit cost functions are positive because there are only two inputs in the production process of each activity. Denoting with subscript $\theta$ the derivative of a function 
with respect to $\theta_{0}$ and using (B6) yields:

$$
\begin{gathered}
A_{L \theta}=\frac{w_{H} w_{L}}{\theta_{0}}\left(A_{L L} A_{H}-A_{L} A_{L H}\right)<0 \\
A_{H \theta}=\frac{w_{H} w_{L}}{\theta_{0}}\left(A_{H L} A_{H}-A_{H H} A_{L}\right)>0 \\
B_{L \theta}=\frac{w_{H} w_{L}}{\theta_{0}}\left(B_{L L} A_{H}-B_{L H} A_{L}\right)<0 \\
B_{H \theta}=\frac{w_{H} w_{L}}{\theta_{0}}\left(B_{H L} A_{H}-B_{H H} A_{L}\right)>0 \\
B_{\theta}=\frac{w_{H} w_{L}}{\theta_{0}}\left(B_{L} A_{H}-B_{H} A_{L}\right) \gtrless 0
\end{gathered}
$$

Consider the slope of the graph of equation (34). The RHS of (34) is increasing in I (the PEG model) and $x$ (the TEG model) and the LHS is increasing in $\theta_{0}$. Therefore a sufficient but hardly necessary condition for a positive slope is that the RHS of (34) is a decreasing function of $\theta_{0}$. The derivative of the RHS of (34) with respect to $\theta_{0}$ is equal to

$$
\Psi(\rho+2 I-n) x\left[B A_{L \theta}+A_{L} B_{\theta}\right]+B_{L \theta} I x
$$

and since $B_{L \theta}<0$, a sufficient condition for a positive slope of (34) is that expression $B A_{L \theta}+$ $A_{L} B_{\theta}$ be negative. In other words, this condition implies that

$$
\frac{\partial\left[A_{L} B\right]}{\partial \theta_{0}}<0
$$

Substituting $A_{L \theta}$ and $B_{\theta}$ given by (B7) and (B11) yields the following sufficient condition for (B12) to be negative

$$
\frac{B A_{L}}{w_{L}}\left[\frac{A_{L L} w_{L}}{A_{L}}+\frac{B_{L} w_{L}}{B}\right]<0 .
$$

Because $B=B_{L} w_{L}+B_{H} w_{H}$, the positive term in this expression is less than one. In addition, differentiating $A_{L} w_{L}+A_{H} w_{H}=1$ with respect to $w_{L}$ and rearranging terms yields $A_{L L} w_{L} / A_{L}=$ $-1-\left(A_{F L} w_{H} / A_{L}\right)$ which establishes the negative sign of expression (B12).

Consider the slope of the graph of equation (35). The RHS increases in $\mathrm{x}$ and I and the LHS decreases in $\theta_{0}$. Therefore a sufficient condition for the negative slope of (35) is that the 


\section{B-4}

RHS is an increasing function of $\theta_{0}$. Differentiating the RHS of (35) with respect to $\theta_{0}$ yields

$$
\psi x(p+2 I-n)\left[A_{H \theta} B+A_{H} B_{\theta}\right]+B_{H \theta} I x
$$

Because $B_{H \theta}>0$, a sufficient condition for the slope of (35) to be negative is that

$$
\frac{A_{H} B A_{L}}{W_{H}}\left(\frac{A_{H H} W_{H}}{A_{H}}+\frac{B_{H} W_{H}}{B}\right) \text { is negative. If this condition }
$$

All terms in the above expression except $A_{H H}$ are positive and $B_{H} w_{H}<B=B_{H} w_{H}+B_{L} w_{L}$. In addition, differentiating expression $A_{L} w_{L}+A_{H} w_{H}=1$ with respect to $w_{H}$ yields $A_{H H} w_{H} / A_{H}=-$ $1-\left(A_{L H} W_{L} / A_{H}\right)$, and therefore the expression in parenthesis is negative as required and (B13) holds.

The above calculations established the positive slope of (34) and the negative slope of (35) in the $\theta_{0}, x$ space for the TEG model and the $\theta_{0}$, I space for the PEG model. The next step of the proof is to examine the vertical intercepts of these curves. Using equations $1=A_{L} w_{L}+$ $A_{H} w_{H}$ and $\sigma w_{L} / w_{H}=\theta_{0}$, yields

$$
w_{H}=\frac{\sigma}{\theta_{0} A_{L}+\sigma A_{H}} \quad, \quad w_{L}=\frac{\theta_{0}}{\theta_{0} A_{L}+\sigma A_{H}}
$$

and consequently we have

$$
B\left(\theta_{0}\right)=B_{L} w_{L}+B_{H} w_{H}=\frac{B_{L} g\left(\theta_{0}\right)}{A_{L}}
$$

where (B14) was used and

$$
g\left(\theta_{0}\right)=\frac{\left[\theta_{0}+\sigma\left(B_{H} / B_{L}\right)\right]}{\left[\theta_{0}+\sigma\left(A_{H} / A_{L}\right)\right]}
$$

Substituting (B15) into (34) yields

$$
\theta_{0}=B_{L} g \Psi(\rho+2 I-n) x+B_{L} I x
$$

Consider the TEG specification of the model first. Equation (B17) can be written as 
where $I=n / 2 \mu>0$. The term in square brackets converges to a strictly positive number as $\theta_{0}$ approaches zero, given condition (36). The left-hand-side of (B18) approaches zero as $\theta_{0}-0^{+}$ because $B_{L}$ decreases in $\theta_{0}$ and cannot be negative. Therefore as $\theta_{0} \rightarrow 0^{+}, x$ has to approach zero. In addition, when $\theta_{0}=1,(\mathrm{~B} 18)$ implies that $\mathrm{x}$ is strictly positive. Therefore, under condition (36), the graph of equation (34) starts at the origin and slopes upward as illustrated in Figure 2. At $\dot{\theta}_{0}=1$, equation (35) is satisfied only if $x=0$ because all the terms of the RHS that depend on $\theta_{0}$ are strictly positive at $\theta_{0}=1$. Therefore, the graph of equation (35) starts at $\theta_{0}=1$ and it is downward sloping. Thus there is a unique intersection with a positive $\mathrm{x}$ and an equilibrium value of $\theta_{0}$ that lies strictly between zero and one.

Similar considerations establish the existence of a unique steady-state equilibrium in the PEG model, where $x=k>0$. By setting $I=0$ in (34) and (35), we obtain implicit expressions for the vertical intercepts

$$
\begin{gathered}
\frac{\theta_{1}}{B_{L}\left(\theta_{1}\right) g\left(\theta_{1}\right)}=\psi(\rho-n) k \\
\frac{\left[1-\left(\theta_{2}\right)^{2}\right] \Psi}{2 A_{H}\left(\theta_{2}\right) B\left(\theta_{2}\right)}=\Psi(\rho-n) k
\end{gathered}
$$

where $\theta_{1}$ and $\theta_{2}$ are the vertical intercepts of (34) and (3.5) in the $\theta_{0}$, I space. Expression: $B_{L}\left(\theta_{1}\right) g\left(\theta_{1}\right)=A_{L}\left(\theta_{1}\right) B\left(\theta_{1}\right)$ increases in $\theta_{1}$ given (B12). In addition, as $\theta_{1}-0^{+}$the LHS of (B19) approaches zero as $k$ approaches zero. Therefore, $d \theta_{1} / d k>0$ and $\theta_{1}$ approaches zero as $k$ approaches zero.

Equation (B20) implies that $\theta_{2}=1$ if $k=0$ because the denominator of the LHS is positive at $\theta_{2}=1$. In addition, (B13) implies that the LHS of (B20) decreases in $\theta_{2}$. Therefore as $\mathrm{k}$ increases, $\theta_{2}$ decreases starting at $\theta_{2}=1$. Thus, at $\mathrm{k}=0, \theta_{1}=0$ and $\theta_{2}=1$ and consequently, there exists a low value of $k$ such that $(B 19)$ and $(B 20)$ are satisfed with $0<\theta_{1}<\theta_{2}<1$. This implies that, under assumption (36), the graphs of equations (34) and (35) have a unique 
there exists a low value of $k$ such that $(B 19)$ and $(B 20)$ are satisfed with $0<\theta_{1}<\theta_{2}<1$. This implies that, under assumption (36), the graphs of equations (34) and (35) have a unique intersection for a low value of $\mathrm{k}$. The unique intersection, which is illustrated in Figure 3 generates an equilibrium value of $\theta_{0}$ which lies strictly between zero and one. 


\section{References}

Berman, E., Bound. J. And Griliches, Z. (1994), "Changes in the Demand for Skilled Labor within US Manufacturing: Evidence from the Annual Survey of Manufacturers," Quarterly Journal of Economics, May, 109, 367-97.

Bhagwati, J., (1995), “Trade and Wages: A Malign Relationship?”, Columbia University, mimeo.

Borjas, G. and V. Ramey, (1994), "Time-Series Evidence on the Sources of Trends in Wage Inequality," American Economic Review Papers and Proceedings, May, 84,.2, 10-16.

Borsook, I., (1987), “Eamings, Ability and International Trade," Journal of International Economics, 22, 281-95.

Burtless. G.. (1995), "International Trade and the Rise in Eamings Inequality," Journal of Economic Literature, 33, 2, 800-816.

Davis. D., (1996a), “Does European Unemployment Prop up American Wages?” Harvard Institute of Economic Research Discussion Paper 1752, March.

Davis, D., (1996b), “Technology, Unemployment, and Relative Wages in a Global Economy." NBER Working Paper 5636, June.

Deardorff, A. and D. Hakura. (1994), "Trade and Wages: What are the Questions?". in Bhagwati and Kosters, (eds), Trade and Wages: Leveling Wages Down?, Washington. D.C.: AEI Press. 76-107.

Dinopoulos. E. and P. Segerstrom. (1996), "The Dynamic Effects of Contingent Tariff Protection." Michigan State University, mimeo.

Dinopoulos. E. and P. Thompson, (1996), "A Contribution to the Empirics of Endogenous Growth." Eastern Economic Journal, forthcoming.

Feenstra. R. and G. Hanson, (1994), "Foreign Investment. Outsourcing and Relative Wages." University of California at Davis, mimeo.

Findlay, R. and H. Kierzkowski, (1983), "Human Capital and International Trade: A Simple General Equilibrium Model," Journal of Political Economy, 91, 957-78.

Freeman. R., (1995), “Are Your Wages Set in Beijing?”, Journal of Economic Perspectives. 9. 3, $15-32$.

Lawrence. R. And M. Slaughter. (1993), "Trade and U.S. Wages: Giant Sucking Sound or Small 
Hiccup?", Brookings Papers of Economic Activity: Microeconomics, Washington, D.C.: Brookings Institution, 161-226.

Richardson, D., (1995), "Income Inequality and Trade: How to Think, What to Conclude," Journal of Economic Perspectives, 9, 3, 33-56.

Sachs, J. And H. Shatz, (1994), "Trade and Jobs in US Manufacturing," Brookings Papers on Economic Activity, 1-84.

Scherer, F. M., (1983), "Concentration, R\&D, and Productivity," Southern Economic Journal, 50, 221-25.

Segerstrom, P., (1995), "Endogenous Growth Without Scale Effects," Michigan State University, mimeo.

Segerstrom. P., T.C.A. Anant and E. Dinopoulos. (1990), "A Schumpeterian Model of the Product Life Cycle," American Economic Review. 80, 1077-91.

Shatz. H. (1996), "Engineers and Scientists in US Manufacturing Trade," Harvard University Kennedy School of Government, mimeo.

Stolper, W. and P. Samuelson, (1941), "Protection and Real Wages," Review of Economic Studies, 9, 1, 58-73.

Wood, A.. (1995), "How Trade Hurt Unskilled Workers," Journal of Economic Perspectives. 9. 3. $57-80$. 